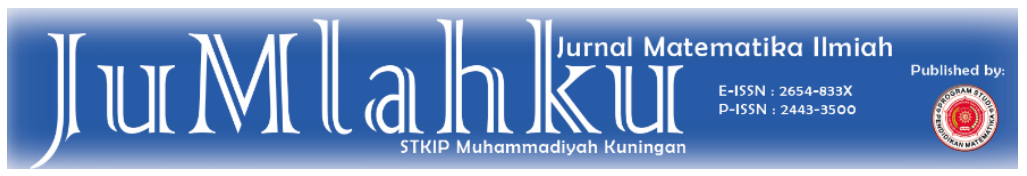

Submited: 2021-07-12

Published: 2021-12-20

\title{
KEMAMPUAN LITERASI MATEMATIKA DITINJAU DARI SELF-EFFICACY PADA MATERI TRIGONOMETRI SISWA KELAS X
}

\author{
Santi Sulistiya ${ }^{1}$, Rochmad $^{2}$, Nuriana Rachmani Dewi ${ }^{3}$ \\ 1,2,3 Universitas Negeri Semarang, Jawa Tengah
}

Corresponding Author: santisulistiya@students.unnes.ac.id

\begin{tabular}{|c|c|}
\hline Article Info & Abstract \\
\hline $\begin{array}{l}\text { Keywords: Mathematical } \\
\text { Literacy, Self-Efficacy, } \\
\text { Trigonometry }\end{array}$ & $\begin{array}{l}\text { The purpose of this research is describe the mathematical } \\
\text { literacy ability of class X SMA Negeri } 1 \text { Sumber in terms of self- } \\
\text { efficacy in trigonometry material. The type of research used is } \\
\text { descriptive qualitative research. Sampling was done by } \\
\text { purposive sampling technique. In this research, three subjects } \\
\text { were taken from the category of students who had high, } \\
\text { medium, and low self-efficacy at SMA Negeri } 1 \text { Sumber. } \\
\text { Collecting data using a questionnaire, mathematical literacy } \\
\text { test, and interview guidelines. The validation test used is a } \\
\text { technical triangulation test. The results showed that of the } \\
\text { three research subjects, students could achieve two to seven } \\
\text { indicators of mathematical literacy. students with low self- } \\
\text { efficacy are only able to fulfill two indicators of mathematical } \\
\text { literacy, namely Communication and Representation. Students } \\
\text { with moderate self-efficacy are able to fulfill four indicators of } \\
\text { mathematical literacy, namely Communication, Using } \\
\text { mathematics tools, Mathematising, and Representation. } \\
\text { Meanwhile, Students with high self-efficacy can fulfill all } \\
\text { indicators of mathematical literacy ability. }\end{array}$ \\
\hline
\end{tabular}


Kata Kunci: Literasi Matematika, SelfEfficacy, Trigonometri
Penelitian ini bertujuan untuk mendeskripsikan kemampuan literasi matematika siswa kelas X SMA Negeri 1 Sumber yang ditinjau dari self-efficacy pada materi trigonometri. Jenis penelitian yang digunakan adalah penelitian deskriptif kualitatif. Pengambilan sampel dilakukan dengan teknik purposive sampling. Dalam penelitian ini diambil tiga subjek penelitian dari kategori siswa yang memiliki self-efficacy tinggi, sedang, dan rendah di SMA Negeri 1 Sumber. Pengumpulan data menggunakan angket, tes literasi matematika, dan pedoman wawancara. Uji validasi yang digunakan adalah uji triangulasi teknik. Hasil penelitian menunjukkan bahwa dari tiga subjek penelitian tersebut, siswa dapat mencapai dua hingga tujuh indikator literasi matematika. Siswa dengan self-efficacy rendah hanya mampu memenuhi dua indikator literasi matematika yaitu Communication, dan Representation. Siswa dengan selfefficacy sedang mampu memenuhi empat indikator literasi matematika yaitu Communication, Using mathematics tools, Mathematising, dan Representation. Sedangkan Siswa dengan self-efficacy tinggi dapat memenuhi semua indikator kemampuan literasi matematika.

\section{PENDAHULUAN}

Pendidikan pada abad ke-21 merupakan pendidikan abad digital yang berorientasi pada masa depan yang ditandai oleh perkembangan teknologi informasi dan komunikasi yang sangat pesat. Pendidikan dituntut memenuhi kebutuhan masyarakat yang selalu berkembang secara dinamis akibat kemajuan ilmu pengetahuan dan teknologi. Implikasinya setiap bangsa termasuk Indonesia harus menyesuaikan dengan tuntutan zaman tersebut.

Menurut Binkley, et al. (2012) untuk mampu hidup di abad ke-21, diperlukan sepuluh keterampilan yang harus dimiliki siswa, keterampilan tersebut antara lain keterampilan berpikir kreatif berpikir kritis, berpikir metakognisi, komunikasi, kolaborasi, literasi informasi, literasi TIK (Teknologi
Informasi

Komunikasi), berkewarganegaraan, bekerja dan berkarir, serta keterampilan responsibilatas individu dan sosial. Dengan demikian maka, salah satu keterampilan yang penting di abad 21 adalah kemampuan literasi. Kemampuan literasi perlu dikembangkan dan dibiasakan oleh setiap individu agar bisa mengikuti perkembangan zaman.

Matematika merupakan salah satu mata pelajaran yang bersifat universal yang memiliki peranan penting dalam dunia pendidikan. Matematika dipelajari di setiap jenjang pendidikan mulai dari TK, SD, SMP, SMA jenjang perguruan tinggi. Matematika dipelajari dan dikembangkan untuk membentuk kemampuan siswa berifikir secara logis, rasional, analitis, sistematis, kritis, dan kreatif (Wardono, et al, 2015). 
Pada abad ke-21 kemampuan berliterasi peserta didik berkaitan erat dengan tuntutan keterampilan membaca yang berujung pada kemampuan memahami informasi secara analitis, kritis, dan reflektif. Akan tetapi, pembelajaran di sekolah saat ini belum mampu mewujudkan hal tersebut. Pada tingkat sekolah menengah (usia 15 tahun) pemahaman membaca peserta didik Indonesia diuji oleh Organisasi untuk Kerja Sama dan Pembangunan Ekonomi (OECDOrganization for Economic Cooperation and Development) dalam Programme for International Student Assessment (PISA).

Peringkat Indonesia merosot dalam evaluasi Programme for International Student Asessment (PISA). Sejak empat tahun terakhir, posisi Indonesia menurun di semua bidang yang diujikan: membaca, matematika, dan sains. Berdasarkan laporan PISA yang dirilis pada tanggal 3 Desember 2019, skor membaca Indonesia ada di peringkat 72 dari 77 negara, lalu skor matematika ada di peringkat 72 dari 78 negara, dan skor sains ada di peringkat 70 dari 78 negara. Tiga skor itu kompak menurun dari tes PISA 2015. Kala itu, skor membaca Indonesia ada di peringkat 65, skor sains peringkat 64, dan skor matematika peringkat 66. Di antara negaranegara Asia Tenggara, Indonesia berada paling bawah bersama Filipina yang mendapat peringkat terakhir dalam membaca dan skor sebelum terakhir di dua bidang lain.

Menurut Permendikbud No.21 tahun 2016 tentang standar isi mata pelajaran matematika kurikulum 2013 lingkup Pendidikan menengah, mata pelajaran matematika wajib dan peminatan memiliki kompetensi umum dengan tujuan agar siswa memiliki kemampuan sebagai berikut (1) Menunjukkan sikap logis, kritis, analitis, kreatif, cermat dan teliti, bertanggung jawab, responsif, dan tidak mudah menyerah dalam memecahkan masala; (2) Memiliki rasa ingin tahu, percaya diri, semangat belajar yang kontinu, pemikiran reflektif dan ketertarikan pada matematika; (3) Memiliki rasa percaya pada daya dan kegunaan matematika, serta sikap kritis yang terbentuk melalui pengalaman belajar; (4) Memiliki sikap terbuka, objektif, dan menghargai karya teman dalam interaksi kelompok maupun aktivitas sehari-hari; (5) Memiliki kemampuan mengkomunikasikan gagasan matematika dengan jelas dan efektif; (6) Menjelaskan pola dan menggunakannya untuk melakukan prediksi dan kecenderungan jangka panjang menggunakannya untuk memprediksi kecenderungan atau memeriksa kesahihan argumen.

Selain dengan software yang sesuai Pada tahun 2006, literasi matematika diperkenalkan ke dalam kurikulum FET. Pengenalannya membuat mata pelajaran yang berorientasi matematis, baik matematika atau literasi matematika wajib untuk semua pelajar FET. Pernyataan kebijakan kurikulum dan penilaian (DBE, 2011). mendefinisikan literasi matematika sebaga subjek yang mengembangkan kompetensi yang memungkinkan pelajar memahami, berpartisipasi, dan berkontribusi pada dunia abad ke-21 dunia yang dicirikan oleh sejumlah literasi matematika dengan cara yang berbeda. Kompetensi tersebut meliputi kemampuan untuk menalar, 
membuat keputusan, memecahkan masalah, mengelola sumber daya, menafsirkan informasi, menjadwalkan acara, dan menggunakan serta menerapkan teknologi.

Ojose (2011) memandang literasi matematika sebagai pengetahuan untuk mengetahui dan menerapkan matematika dasar dalam kehidupan sehari-hari. Pengetahuan dasar yang dimaksudkan tidak hanya sekedar pengetahuan akademik saja melainkan juga aplikasi dari matematika yang digunakan dalam kehidupan seharihari. Sementara itu, Stacey (2010) menyatakan bahwa literasi matematika dalam PISA berfokus pada kemampuan siswa dalam menganalisis, memberikan alasan, dan menyampaikan ide secara efektif, merumuskan, memecahkan, dan menginterpretasi

masalah-masalah matematika dalam berbagai bentuk dan situasi. Sedangkan literasi matematika dalam Draft Mathematics Framework PISA 2015 didefinisikan sebagai kemampuan seseorang untuk merumuskan, menggunakan, dan menafsirkan matematika dalam berbagai konteks yang mencakup penalaran secara matematis dan menggunakan konsep, prosedur, fakta dan alat matematis untuk menggambarkan, menjelaskan dan memprediksi fenomena. Hal ini membantu individu untuk mengenali peran matematika di dunia dan untuk membuat keputusan yang baik sebagaimana dibutuhkan oleh masyarakat yang konstruktif, terlibat dan reflektif. Berdasarkan beberapa pendapat tersebut, dapat disimpulkan bahwa literasi matematika merupakan kemampuan 152 matematika yang dapat digunakan seseorang untuk memecahkan masalah dalam kehidupan sehari- hari.

Kemampuan literasi matematika merupakan topik penting yang dikaji di berbagai negara. Ozgen (2013) mengkaji tentang literasi matematika siswa di Turki dan hubungannya dengan dunia nyata. Hasil menunjukkan bahwa konsep literasi matematika dan hubungannya dengan dunia nyata saling melengkapi. Selanjutnya Sandström et al. (2013) melakukan penelitian tentang penguasaan matematika siswa di Swedia terhadap kemampuan literasi matematika. Penelitian menemukan bahwa siswa mengalami kesulitan dalam tugas matematika yang mengandung angka dan soal cerita.

Selain pembentukan keterampilan literasi matematika, pembelajaran matematika yang baik juga harus mempertimbangkan masalah pisikologis siswa di mana dengan perkembangan aspek pisikologis positif diharapkan dapat mempengaruhi pembentukan keterampilan lietarasi matematika siswa. Salah satu aspek psikologis yang harus dikembangkan dalam pembelajaran mateamatika adalah selfefficacy yang merupakan konsep yang paling penting dari sifat aktif individu. Self-efficacy oleh Bandura dalam kapasitasnya untuk dapat mengatur kegiatan yang diperlukan yang diperlukan untuk kinerja tertentu, dan berhasil melakukannya. Dengan kata lain, siswa yang memiliki self-efficacy dapat melakukan pekerjaan dengan baik.

Proses pembelajaran ada beberapa faktor yang mempengaruhi yaitu faktor psikologi dalam diri siswa, kesuksesan 
bukan dipengaruhi oleh pengetahuan saja (hard skill) tapi juga dipengaruhi kemampuan mengelola diri (soft skill) (Purwanti \& Mujiasih, 2021). Kemampuan literasi matematika diperlukan siswa untuk menerapkan informasi matematika dalam kehidupan sehari-hari. Selain itu, soft skill berupa self-efficacy atau kenyakinan diri juga memberikan pengaruh terhadap keberhasilan siswa menyelesaikan suatu persoalan. Bandura menyatakan bahwa selfefficacy diartikan kepercayaan seseorang tentang kemampuan dirinya untuk menghasilkan prestasi yang mempengaruhi kejadian dalam kehidupan nyata. Menurut Zimmermen, self-efficacy merupakan penilaian pribadi mengenai kemampuan individu untuk mengatur dan melaksanakan program kerjanya dalammencapai tujuan ditentukan dan ia akan menilai tingkat, keumuman, dan kekuatan atas semua kegiatan dan konteks (D. H. Schunk \& Zimmerman, 2007). Bandura \& Adam menyebutkan bahwa self-efficacy ada 3 dimensi yaitu dimensi magnitude, strength, dan generally (A Bandura, 1977). Dimensi magnitude menekankan pada tingkat kesulitan yang diyakini seseorang dapat diselesaikan, dimensi strength berkaitan dengan tingkat kekuatan atau kelemahan kenyakinan seseorang mengenai diri yang dirasakan, dan dimensi generally berkaitan dengan perasaan mampu dimiliki seseorang sebagai tindakan yang dimilikinya untuk menguasai tugas dalam kondisi tertentu. Self-efficacy untuk literasi matematika pada siswa dapat berubah dan ditingkatkan, yaitu dengan menggunakan strategi pembelajaran yang tepat, seperti membantu siswa membangun tujuan belajar, memastikan siswa bekerja keras, dan selalu memberi umpan balik atas respon siswa (Ozgen, K., \& Bindak, 2011). Salah satunya pembelajaran yang melibatkan siswa aktif dan meningkatkan berpikir matematis sehingga memungkinkan siswa untuk belajar secara optimal dan menjunjung literasi matematika yaitu disvocery learning. Discovery learning merupakan suatu pembelajaran yang menitikberatkan pada kegiatan siswa dalam belajar dan menemukan sendiri konsep dan teorinya. Penelitian Mawaddah, Kartono, \& Suyitno menyatakan bahwa model discovery learning meningkatan kemampuan matematis (Mawaddah et al., 2015) (Mawaddah et al., 2015).

Trigonometri adalah salah satu materi yang penggunaan ilmunya banyak digunakan dalam berbagai bidang. Penggunaannya yang erat dengan segitiga banyak digunakan dalam masalah kontekstual yang hubungannya dengan geometri bidang seperti jarak dan luas. Materi ini menjadi salah satu yang sulit dikuasai oleh peserta didik. Diani (2015) menyatakan permasalahan peserta didik dalam mempelajari trigonometri adalah kesulitan memilih dan menerapkan konsep yang tepat dalam penyelesaian masalah nyata. Hal ini tentunya sangat erat dengan kemampuan literasi matematika dari peserta didik tersebut yang juga masih kurang.

\section{METODE}

Metode penelitian yang digunakan adalah metode penelitian deskriptif kualitatif yang dilakukan di SMA Negeri 1 Sumber. Penelitian dilakukan pada siswa kelas X IPA 
tahun ajaran 2020/2021 pada semester genap. Dari kelas X IPA tersebut, dipilih masing-masing satu siswa untuk tiap kategori self-efficacy tinggi, self-efficacy sedang, dan self-efficacy rendah.

Teknik pengumpulan data dalam penelitian ini menggunakan tes untuk memperoleh data kemampuan literasi matematika dan angket untuk mengetahui karakter rasa keyakinan diri (self-efficacy) siswa. Metode wawancara digunakan sebagai penguat dalam memperoleh informasi dari siswa tentang proses pengerjaan soal tes literasi matematika. Pemeriksaan keabsahan data dalam penelitian ini menggunakan triangulasi teknik, yaitu membandingkan hasil tes literasi matematika dan hasil wawancara dari sumber yang sama pada subjek penelitian. Data yang diperoleh dari sumber yang sama dapat dikatakan kredibel, jika hasil tes dan wawancara saling bersesuaian. Data dalam penelitian ini dianalisis mengacu pada proses analisis data kualitatif yaitu reduksi data, penyajian data, dan penarikan kesimpulan.

\section{HASIL DAN PEMBAHASAN}

Berdasarkan permasalahan dan metode penelitian yang telah diuraikan di atas, maka langkah pertama yaitu menentukan subjek penelitian. Subjek penelitian diperoleh dari hasil angket selfefficacy siswa yang diberikan kepada siswa kelas X IPA. Menurut A Bandura (1977), dimensi-dimensi self-efficacy yang digunakan sebagai dasar bagi pengukuran terhadap self-efficacy individu adalah : (a)Magnitude. Dimensi ini berkaitan dengan 154 tingkat kesulitan tugas yang diyakini oleh seseorang untuk dapat diselesaikan. Jika individu dihadapkan pada masalah atau tugas-tugas yang disusun menurut tingkat kesulitan tertentu maka self-efficacy nya akan jatuh pada tugas-tugas yang mudah, sedang, dan sulit sesuai dengan batas kemampuan yang dirasakan untuk memenuhi tuntutan perilaku yang dibutuhkan bagi masing-masing tingkatnya tersebut. (b) Strength. Dimensi ini berkaitan dengan tingkat kekuatan atau kelemahan keyakinan individu tentang kemampuan yang dimilikinya. Individu dengan self-efficacy kuat mengenai kemampuannya cenderung pantang menyerah dan ulet dalam meningkatkan usahanya walaupun menghadapi rintangan. Sebaliknya individu dengan self-efficacy lemah cenderung mudah terguncang oleh hambatan kecil dalam menyelesaikan tugasnya; (c)Generality. Dimensi ini merupakan dimensi yang berkaitan dengan keluasan bidang tugas yang dilakukan.

Dari hasil angket kemudian didiskusikan dengan guru mata pelajaran matematika untuk pengambilan sampel. Hasilnya diperoleh siswa dengan selfefficacy tinggi, dan rendah. Pengambilan sampel hanya tiga orang siswa untuk kelas $X$ IPA. Selain itu, siswa yang dipilih juga dengan pertimbangan bahwa siswa tersebut dapat berkomunikasi dengan baik, serta memiliki kemampuan matematika yang setara. Subjek penelitian yang diambil terdapat pada Tabel 1 berikut ini. 
Tabel 1. Daftar subjek penelitian

\begin{tabular}{cccc}
\hline No & Siswa & Kelas & $\begin{array}{c}\text { Kategori } \\
\text { Self-efficacy }\end{array}$ \\
\hline 1 & $A_{1}$ & X IPA 1 & Rendah \\
2 & $A_{2}$ & X IPA 2 & Sedang \\
3 & $A_{3}$ & X IPA 3 & Tinggi \\
\hline
\end{tabular}

Setelah diperoleh subjek penelitian, selanjutnya peneliti memberikan soal tes literasi matematika. Untuk melihat kesesuaian jawaban siswa maka peneliti kemudian melakukan wawancara secara virtual dengan subjek penelitian. Hal ini selain digunakan untuk memeriksa keabsahan data, juga dilakukan agar peneliti dapat mengetahui lebih mendalam mengenai bagaimana siswa menyelesaikan persoalan. Berikut pembahasan mengenai kemampuan literasi matematika siswa. Indikator kemampuan literasi yang digunakan dalam penelitian ini adalah (a) Communication (Komunikasi), (b) Mathematising (Matematisasi), (c) Representation (Representasi), (d) Reasoning and argument (Penalaran dan pemberian alasan),

(e) Devising strategies for solving problems (Merancang strategi).

(f) Using symbolic, formal and technical language and operation (Penggunaan simbol).

(g) Using mathematics tools (Penggunaan alat matematik).
Kemampuan Literasi Matematika Siswa yang memiliki self-efficacy rendah

Tabel 2. Jawaban Subjek Penelitian $A_{1}$

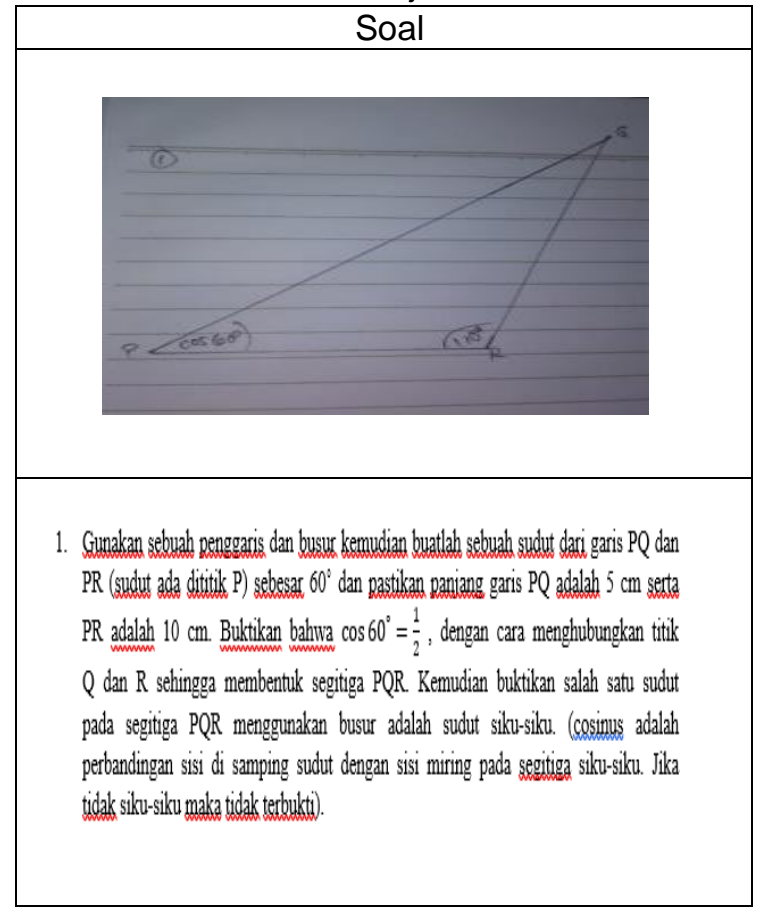

Berdasarkan tabel 2 di atas, diperoleh bahwa apabila ditinjau dari indikator literasi matematika, subjek $A_{1}$ masih kesulitan dalam menghubungkan masalah dan memberikan alasan dalam mencari solusi, belum menggunakan alat-alat untuk menyelesaikan masalah. masih kesulitan menyajikan permasalahan dalam bentuk gambar atau sketsa, dan kesulitan dalam menyampaikan permasalahan serta solusi 
matematika dan penyelesaian masalah. Dari ketujuh indikator kemampuan literasi, ternyata pada siswa yang memiliki selfeffeicacy rendah hanya mampu mencapai dua buah indikator saja yaitu communication dan representation.

Kemampuan Literasi Matematika Siswa yang memiliki self-efficacy sedang

Tabel 3. Jawaban Subjek Penelitian $\mathrm{A}_{2}$

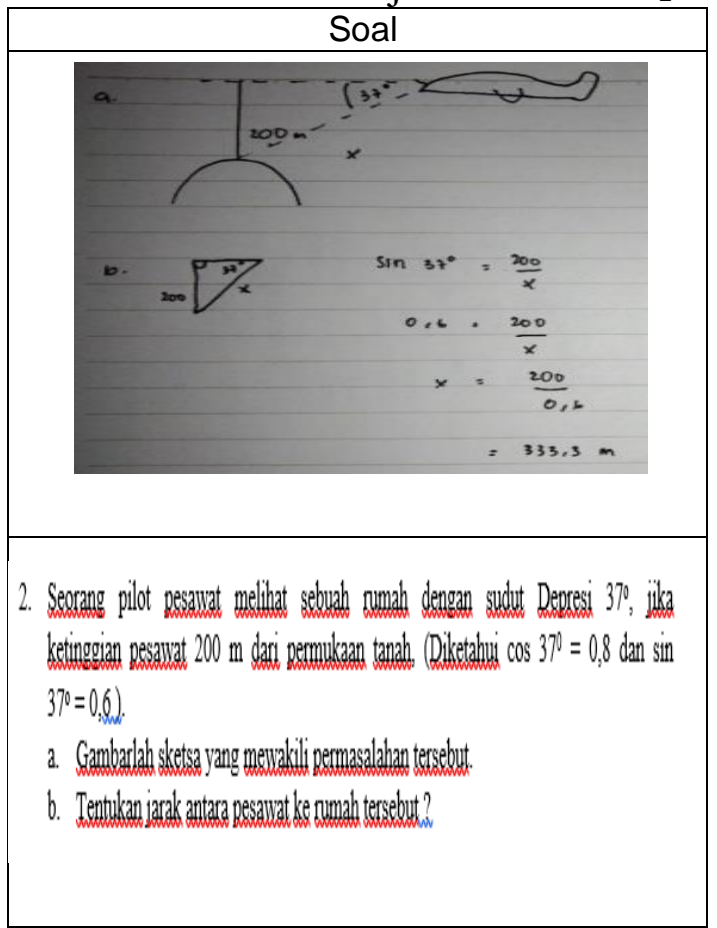

Berdasarkan tabel 3 di atas, diperoleh bahwa apabila ditinjau dari indikator literasi matematika, subjek $A_{2}$ masih kesulitan 156 dalam menghubungkan masalah dan memberikan alasan dalam mencari solusi, dan masih kesulitan dalam menggunakan bahasa dan operasi simbolis, formal dan teknis, serta melibatkan pemahaman, interpretasi, manipulasi, dan penggunaan ekspresi simbolis dalam konteks matematika kemudian membuat solusi matematika. Dari ketujuh indikator kemampuan literasi, ternyata pada siswa yang memiliki selfefficacy sedang hanya mampu empat indikator literasi matematika yaitu Communication, Using mathematics tools, Mathematising, dan Representation.

Kemampuan Literasi Matematika Siswa yang memiliki self-efficacy tinggi

Tabel 4. Jawaban Subjek Penelitian $A_{3}$

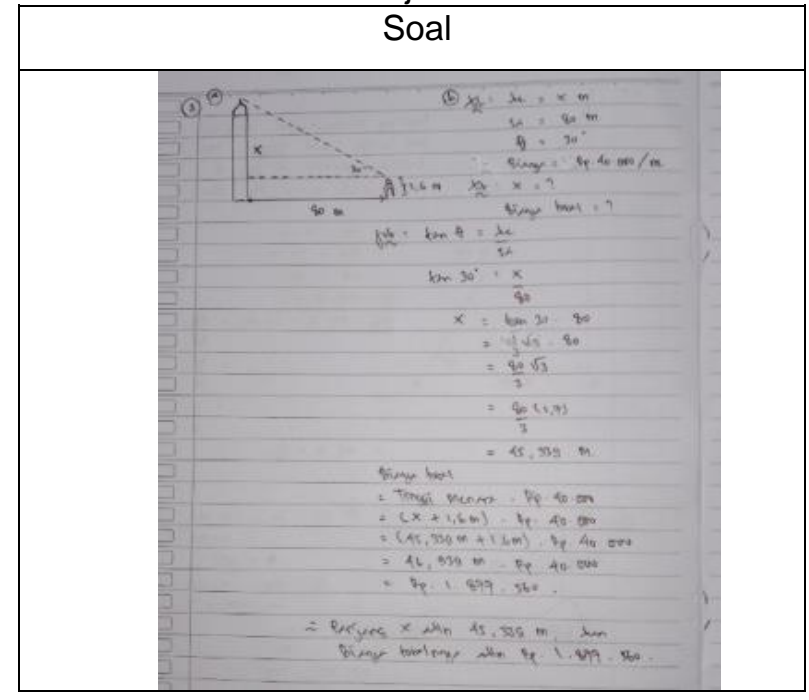




\begin{tabular}{|c|}
\hline Soal \\
\hline 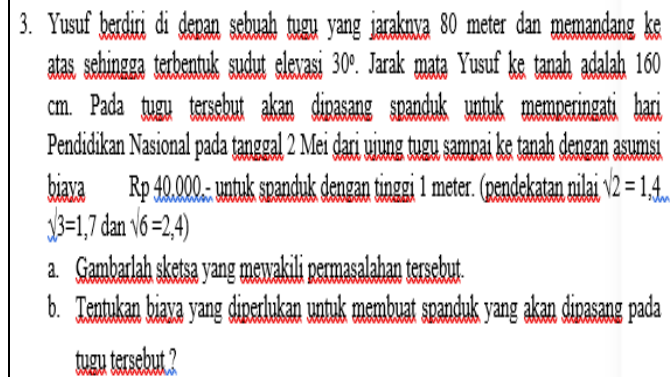 \\
\hline
\end{tabular}

Berdasarkan tabel 4 di atas, diperoleh bahwa apabila ditinjau dari indikator literasi matematika, subjek $A_{3}$ sudah mampu memenuhi semua indikator kemampuan literasi matematika. Dari ketujuh indikator kemampuan literasi, ternyata pada siswa yang memiliki self-efficacy tinggi sudah mampu memenuhi semua indikator yaitu Communication, Mathematising, Representation, reasoning and argument, Devising strategies for solving problems, Using symbolic, formal and technical language and operation dan Using mathematics tools.

Wawancara dilakukan setelah melaksanakan tes kemampuan literasi matematika, wawancara dalam penelitian ini adalah observasi langsung yang dilakukan secara virtual menggunkan Zoom Meeting. Pertanyaan 1: Apakah anda menggunakan alat bantu dalam menggambar saat mengerjakan soal?

Dalam menjawab pertanyaan ini $A_{1}, A_{2}, A_{3}$ adalah sama, yaitu mereka menjawab menggunakan alat bantu dalam menggambar.
Pertanyaan 2: Apa yang menjadi kendala awal saat mengerjakan soal?

Dalam menjawab pertanyaan ini $A_{1}, A_{2}, A_{3}$ adalah sama, yaitu mereka menjawab kesulitan dalam menerjemahkan soal cerita ke dalam bentuk simbol matematika.

Pertanyaan 3: Bagaimana dengan soal kemampuan literasi yang sudah Anda kerjakan?

Dalam menjawab pertanyaan ini, $A_{1}$ menjawab cukup menyenangkan karena tertantang untuk menemukan solusi sendiri, $\mathrm{A}_{2}$ menjawab bagus karena kami dilatih mandiri untuk mengerjakan soal, $A_{3}$ menjawab seru karena berlangsung secara virtual

Pertanyaan 4: Apakah sekarang anda sudah memahami materi trigonometri?

Dalam menjawab pertanyaan ini $A_{1}, A_{2}, A_{3}$ adalah sama, yaitu mereka menjawab sudah memahami materi trigonometri dengan baik. Pertanyaan 5: Apakah harapan anda untuk pembelajaran saat ini?

Dalam menjawab pertanyaan ini $A_{1}, A_{2}, A_{3}$ adalah sama, yaitu mereka mengharapkan agar bisa sekolah secara tatap muka secepatnya.

\section{PENUTUP}

\section{Simpulan}

Kemampuan Literasi Matematika dan Self-efficacy merupakan variabel yang penting dalam proses pembelajaran matematika. Banyak yang beranggapan bahwa matematika merupakan pelajaran yang sulit. Akan tetapi di depan siswa yang memiliki kemampuan self-efficacy yang tinggi, maka matematika tidak lagi sulit untuk dipelajari, tentumya melalaui kegiatan 
menyelesaikan soal-soal yang sederhana ke seolah yang lebih sulit, dan mampu dilewati. Semakin siswa terlatih menyelesaikan soalsoal matematika maka akan menambah kepercayaan diri dalam menyelesaikannya. Berdasarkan uraian yang telah dijelaskan pada hasil dan pembahasan di atas dapat disimpulkan bahwa siswa dengan selfefficacy rendah hanya mampu memenuhi dua indikator literasi matematika yaitu Communication, dan Representation. Siswa dengan self-efficacy sedang mampu memenuhi empat indikator literasi matematika yaitu Communication, Using mathematics tools, Mathematising, dan Representation. Sedangkan Siswa dengan self-efficacy tinggi dapat memenuhi semua indikator kemampuan literasi matematika.

\section{DAFTAR PUSTAKA}

Binkley,M et al. (2012). Defining TwentyFirst Century Skill. London: Springer

Bandura, A. (1977). Self-efficacy: Toward a unifying theory of behavioral change.

[DBE], D. of B. E. (2011). Curriculum and Assessment Policy Statement 10-12 (General): Mathematical Literacy. Department of Education.

Diani, T. R. C. (2015). Pengaruh Pembelajaran Berbantu E-learning Schoology pada Materi Perbandingan Trigonometri Kelas $X$ TPMI SMK Ma'arif 4 Kebumen Tahun Pelajaran 2014/205. Jurnal EKUIVALENPendidikan Matematika, 18(2): 163168.

Mawaddah, N., Suyitno, H., \& Kartono. (2015). Discovery Learning Model Learning with Metacognitive Approaches to Improve Metacognition and Mathematical Creative Thinking Ability. Unnes Journal of Mathematics Education Research.

OECD. (2012). PISA 2012 Assessment Framework.

https://www.oecd.org/pisa/pisaproducts/ PISA\%202012\%20framework\%20e book_final.pdf

OECD. (2013). PISA 2006 technical report. OECD. (2016). PISA 2015 Result in Focus. https://www.oecd.org/pisa/pisa-2015results-in-focus.pdf

Ojose, B. (2011). "Mathematics Literacy: Are We Able to Put the Mathematics We Learning Into Everyday Use?". Journal of Mathematics Education, 4 (1): 89100.

Ozgen, K., \& Bindak, R. (2011). Determination of Self-Efficacy Beliefs of High School Students Towards Math Literacy. Educational Science: Theory \& Practice, 11(2), 1085-1089.

Ozgen, K. (2013). "Self-Efficacy Beliefs In Mathematical Literacy and Connections Between Mathematics and Real World: The Case of High School Students". Juornal of International Education Research, 9 (4): 305-316.

Permendikbud No.21 tahun 2016 Tentang Standar Isi Mata Pelajaran Matematika Kurikulum 2013 Lingkup Pendidikan Menengah

Purwanti, K. L., \& Mujiasih. (2021). Kemampuan literasi matematika siswa Madrasah Ibtidaiyah ditinjau dari SelfEfficacy. Journal of Integrated Elementary Education, 1(1), 50-65. http://www.tjyybjb.ac.cn/CN/article/dow 
nloadArticleFile.do?attachType=PDF\&i $\mathrm{d}=9987$

Sandström, M., Nilsson, L., \& Lilja, J. 2013. "Displaying Mathematical Literacy Pupils' Talk about Mathematical Activities". Journal of Curriculum and Teaching, 2 (2): 55-61.

Schunk, D. H. (1991). Self-efficacy and academic motivation. Educational Psychologist, 26, 207-231.

Stacey, K. 2010. "Mathematical and Scientific Literacy Around the World". Journal of Science and Mathematics Education in Southeast Asia, 33 (1): 116.

Wardono, Waluya, S.B., Mariani, S., \& D, S. Candra. 2015. "Mathematics Literacy on Problem Based Learning with Indonesian Realistic Mathematics Education Approach Assisted ELearning Edmodo". Journal of Physics: Conference Series 693. 